Volume 8. No. 10, October 2020

International Journal of Emerging Trends in Engineering Research

Available Online at http://www.warse.org/IJETER/static/pdf/file/ijeter318102020.pdf

https://doi.org/10.30534/ijeter/2020/318102020

\title{
Investigating the spatial patterns of aerosol index and cloud radiative forcing inferred from the OMI and CERES sensors
}

\author{
N.S.M.P. Latha Devi ${ }^{1}$, Kanike Raghavendra Kumar ${ }^{2}$ \\ ${ }^{1}$ Department of Physics, Koneru Lakshmaiah Education Foundation (KLEF), Vaddeswaram 522502, Guntur, \\ Andhra Pradesh, India, Email: nsmplathadevi2020@ gmail.com \\ ${ }^{2}$ Department of Physics, Koneru Lakshmaiah Education Foundation (KLEF), Vaddeswaram 522502, Guntur, \\ Andhra Pradesh, India, Email: rkkanike@ kluniversity.in
}

\begin{abstract}
The work reported here demonstrates the spatial changes observed in the aerosol index (AI) parameter derived from the Ozone Monitoring Instrument (OMI) sensor for the period 2002-2016 over East China. The results revealed a strong spatial heterogeneity in AI values over the East China during the study period. We observed significant change in spatial AI from increasing from the South to North of study domain attributed to impact of dust particles transported from Desert regions located in the Northwest of China. It is noted from the spatial relative tendencies that the highest values of AI was found in most provinces of study domain. We elaborately discussed the spatial patterns of AI on seasonal also for the period over East China and strong results were established over the domain. Further, the short-wave cloud radiative forcing (SWCRF) distribution revealed the highest (-180 $\left.\mathrm{Wm}^{-2}\right)$ and lowest $\left(-110 \mathrm{Wm}^{-2}\right)$ values during JJA and DJF, respectively. While the long-wave CRF (LWCRF) values were seen prominent in almost the entire study area, with the high $\left(60 \mathrm{~W} \mathrm{~m}^{-2}\right)$ in JJA and low during MAM over the southeastern sites of study domain. Also, we observed lower magnitudes and association of CRFs in the East of the study region.
\end{abstract}

Key words : OMI; CERES; Aerosol Index; Cloud radiative forcing; East China.

\section{INTRODUCTION}

Atmospheric aerosols include tiny liquid and solid particles suspended in the air [1], which affects the global climate system. Aerosols are one of the most variable components of the Earth's atmosphere that have been recognized as a major factor influencing the Earth's radiative balance and climate [2]. They are one of the major uncertainties in global climate change and they are also responsible for many atmospheric effects. They have ability to scatter and absorb radiation as well change the microphysics of clouds through both direct and indirect effects, respectively [3] [4]. Aerosols have also been concerned in health effects and visibility reduction in urban and regional areas [5]. Ground-based sites are commonly regarded as the most reliable and accurate approach to acquire aerosol products [6] - [10], while they offer measurements at small center regions and fail to provide a global view of aerosol distribution. Therefore, remote sensing satellites have been employed for retrieving aerosol products to enlarge their spatial coverage [11] - [13].

Over East China, the association between radiation and aerosols which is highly essential in understanding the climate change are not well understood or investigated in depth. The reason might be the lack of observations and analysis related to the parameters. However, none of the authors have yet been much concentrated and conducted the investigation in studying their distributions and heterogeneities and further assessment of regional climate change over East China. To the best of our knowledge, this work dealt in studying the long-term relationships between aerosol and cloud radaitive forcing parameters, and strongly believe provides an opportunity to fill the knowledge gap in the country. The main objectives of this study include deepening the analysis and investigation of spatial heterogeneity (mean and trends) involved in the AI parameter over East China derived from the OMI sensor. Besides, we have carried out and assessed the net (longwave+shortwave) cloud radiative forcing (CRF) data sets obtained from the CERES in East China and inferred the link existed between aerosols and radiation.

\section{DATA AND METHODS}

\subsection{Study Domain}

The selected study domain is East China, situated approximately $24-38^{\circ} \mathrm{N}$ and $113-123^{\circ} \mathrm{E}$. The study area is located in the subtropical Asian monsoon zone with four distinctive seasons: spring (March-May), summer (June-August), autumn/fall (September-November), and 
winter (December-February). The southern portion of East China is a subtropical monsoon climate region, and the North area is a temperate monsoon climate region. It has cold and dry weather with scanty precipitation in the winter. In contrast, it has a hot and humid atmosphere with plenty of rainfall in summer because of the prevailing southeastern winds which carry marine air masses to the land, occasionally experiencing cyclones and typhoons. All of these lucrative conditions create an ideal bed to study, understand and investigate the effect or impact imposed on clouds due to the atmospheric aerosols, and in turn, assess the regional climate change [13] - [17].

\subsection{Satellite data}

\subsubsection{The OMI Sensor}

The OMI sensor of NASA's EOS onboard the Aura satellite is actively working since August 2004 and uses the same retrieval algorithm as TOMS. It has a nadir-viewing imaging spectroradiometer with measuring solar radiance (TOA) in the spectrum range of $(270-500 \mathrm{~nm})$ in visible and UV regions with high spatial resolutions of $13 \times 24 \mathrm{~km}^{2}$ on daily coverage over the globe [18]. Though initially designed to retrieve data on trace gases such as $\mathrm{NO}_{2}, \mathrm{SO}_{2}$, and $\mathrm{O}_{3}$, OMI's wavelength range of about $400 \mathrm{~nm}$ allows the detection of elevated layers of absorbing aerosols hence providing valuable information on the aerosol type of a particular region. In this study the improved Level-2 OMAERUV (UVAI) derived from the websitehttp://disc.gsfc.nasa.gov/Aura/OMI/omaero_v003.sht $\mathrm{ml}$ for the study period 2005-2013.

UVAI is an OMI-derived total backscattered UV radiation ratio from the atmosphere with (absorption) aerosol and without aerosols particles (pure scattering), respectively. Quantitatively, it is defined as:

$$
U V A I=100 \log _{10}\left[\frac{I_{360}{ }^{\text {Meas }}}{I_{360} \text { Calc }}\right]
$$

where, $I_{360}{ }^{\text {Meas }}$ and $I_{360}{ }^{\text {Calc }}$ reflects the measured and calculated radiance for $360 \mathrm{~nm}$ respectively, for a Rayleigh atmosphere. Further, its values varies between positive and negative decimal points including zero (with Clouds), the former is associated with absorbing aerosols while the later highlights the presence of non-absorbing aerosols types (e.g., sulfates) [17] - [19]. In addition, the present work, considered only the positive values of UVAI.

\subsubsection{The CERES instrument}

The CERES sensor flies aboard the Terra, Aqua, and Joint Polar Satellite System-1 (JPSS-1) with a field of view 20km and $24 \mathrm{~km}$ respectively and is operational for more than a decade. CERES instrument is capable to work in three spectral channels as $0.3-5 \mu \mathrm{m}, 8-12 \mu \mathrm{m}$, and $0.3-200 \mu \mathrm{m}$, for shortwave, window and total channel, work on the principle of precision thermistor bolometer detectors. However, in comparisons to Terra and Aqua, CERES recommends long-term stability in TOA flux of $0.3 \mathrm{~W} \mathrm{~m}^{-2}$ decade $^{-1}$ for shortwave (SW) and $0.2 \mathrm{~W} \mathrm{~m}^{-2}$ decade $^{-1}$ for longwave (LW), at the $95 \%$ confidence level [20] - [22].

In a recent past CERES project has developed a unique set of data products including cloud retrievals tailored for the ERB applications from collocated Moderate Resolution Imaging Spectroradiometer (MODIS) and Visible Infrared Imaging Radiometer Suite (VIIRS) imagers. Further, following the radiative transfer model CERES sensor is capable to determine surface radiative fluxes in the atmosphere [23]. however, based on recent study annual mean CERES surface radiative fluxes were found to be agree well with the surface measurements to $6 \mathrm{~W} \mathrm{~m}^{-2}(1 \sigma)$ for downward LW, $3 \mathrm{~W} \mathrm{~m}^{-2}$ for upward LW, $4 \mathrm{~W} \mathrm{~m}^{-2}$ for downward SW, and $3 \mathrm{~W} \mathrm{~m}^{-2}$ for upward SW.

\subsubsection{Statistical Methods}

The linear regression statistical approach is capable to quantify and statistically estimate the trends of a long term series data of a particular geophysical variable. In the present study, the same technique was adopted for annual and seasonal trends analysis in AI. The method previously used in other related studies [24] has a practical usage of simply quantifying the direction and magnitude of the trend in a $t$ data. Following this method, a linear trend model (Eq. 2) was adopted:

$$
Y_{t}=c+\omega * X_{t}+\varepsilon
$$

where, $Y_{t}$, c and $X_{t}$ represent the geophysical variable, $c$ is the offset (y-intercept) and $X_{t}$ is the independent variable representing time, respectively. However, $\omega$ is the trend estimate of the $Y_{t}$ under consideration, while $\varepsilon$ is the noise in the time series. The statistical significance of the estimated trends was further tested using the method developed by Weatherhead et al. [23]. Adding to this, trends are considered significant at a p-value of 0.05 or a $95 \%$ confidence interval when $\left|\frac{\omega}{\delta}\right|>2$, whereas trends are considered significant at a 90\% confidence level when $1.5<\left|\frac{\omega}{\delta}\right|<2$; here $\delta$ define the standard deviation of the slope affiliated with the linear regression.

The relative change in AI (which relates the current with initial AI values) can be used to quantitatively describe the 
inter-annual variations in AI. In the present work, the annual and seasonal relative changes in AI are computed using the expression given in Boiyo et al. [24].

\section{RESULTS AND DISCUSSION}

\subsection{Spatial distribution of AI}

The annual mean spatial distribution of AI is shown in Figure 1 plotted for the period from 2002-2016 over East China. The spatial gradient of AI showed a gradual decrease from the North to South of the considered study domain (Figure 1). High AI $(>1.1)$ and low AI $(<0.8)$ with moderate values of 0.8-1.1 were noticed in the south, north and central portions of East China. The high AI in north part during the spring is attributed to dominance of aerosols from natural sources, besides the greater impact of transport of dust particles from the desert regions located in Northwest of China. The low occurrence of dust transportation in the south regions of East China resulted in lower values of AI. Also, the northern parts of the study domain (over the western Shandong province) associated with the large density of population and intense anthropogenic activities resulting in a large accumulation of fine-mode particles with moderate to high values of AI. Apart from, low AI $(<0.8)$ was evidenced over Shanghai, it is a heavily polluted city situated close to the marine environment enriched with coarse salt particles. While low AI $(<0.8)$ values were observed in the southern regions of study domain are highly vegetated (large NDVI) with more amount of precipitation rate [26].

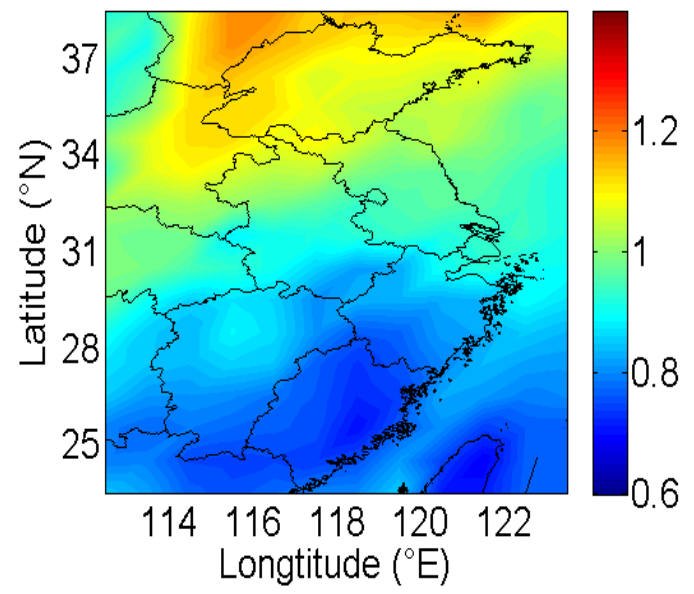

Figure. 1. Spatial distribution of aerosol index (AI) derived from the OMI sensor observed over East China averaged for 2002-2016.

Figure 2 presents the spatial distribution of seasonal values of AI with its maximum ( $>1.2)$ in winter and minimum in summer $(<0.8)$. The highest AI values appeared in the urban area of Shandong province with dense population and large prone to desert dust particles. Several investigators have also reported the persistence of high $\mathrm{AI}$ in the winter over the different regions of the world [15], [25] - [28]. However, the low AI values $(<0.8)$ were mainly found in most of provinces during the summer indicating that aerosols mainly of anthropogenic origin which is agreement with several previous studies conducted over China [10], [15].

\subsection{Spatial tendencies in optical properties}

The spatial relative tendencies of AI obtained for the seasonal means over East China for the 18 $\square$ year period (2000-2017) are presented in Figure 3. The spatial annual mean tendencies of AI were noticed to be positive in the north of the study domain. On seasonal basis, the relative tendencies of AI showed highest values in the winter and lowest in the spring which is quite similar to that found in the seasonal means of $\mathrm{AI}$ over the study domain. It is further evident and revealed that the trends of AI are increasing rapidly in the north of the study domain dominantly due to the mechanism played by the dust particles originated from the Northwest of China. Also, the increasing trends of $\mathrm{AI}$ in winter is associated with the heating occurred over the urban environments to avoid the coldest winters.

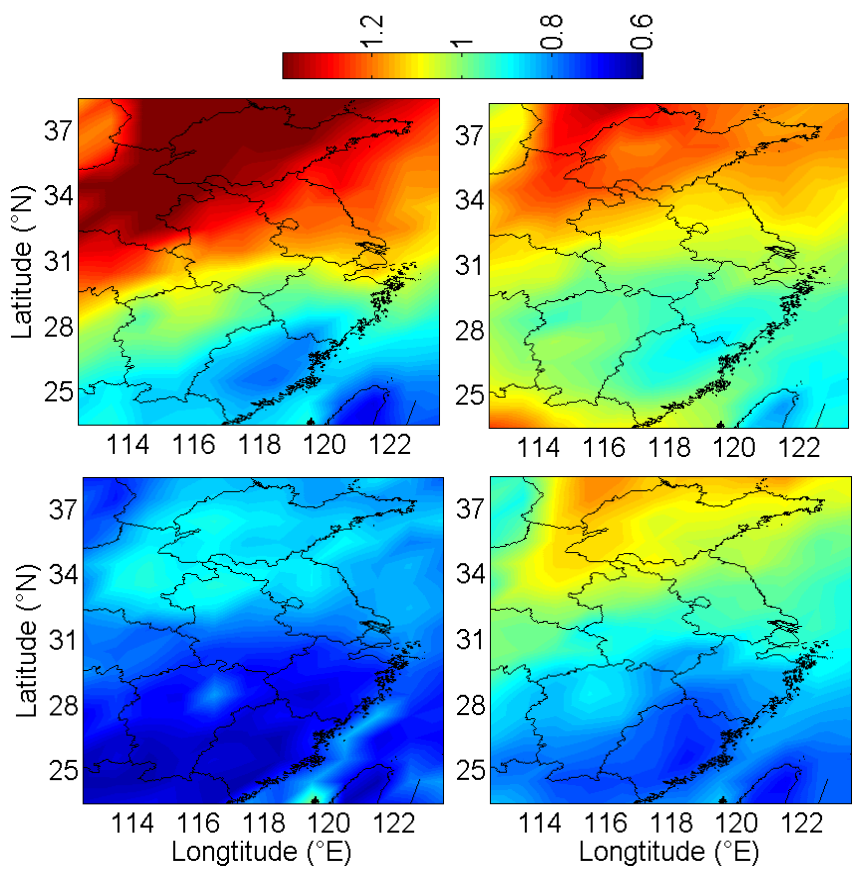

Figure. 2. Spatial changes of AI observed from the OMI sensor in different seasons over the study domain during 2002-2016. The presentation of seasons is from left to right: (top panels) winter and spring and (bottom panels) summer and autumn.

\subsection{Spatial patterns of cloud radiative forcing}

Figure 4 shows the seasonal spatial distributions of CRF for the period from 2004 to 2016 over the study domain. It is found that CRF has an obvious impact on the Southeast China. The spatial gradient of the SWCRF values generally increases from southern to eastern parts of the study domain (figure not shown). The larger negative values of SWCRF 
$\left(-120 \mathrm{~W} \mathrm{~m}^{-2}\right)$ were noticed in the southeastern parts of the study region during MAM. However, the weak negative values of SWCRF were observed in the eastern parts of the domain during DJF. The southern part of the study domain showed strong negative values $\left(-80 \mathrm{~W} \mathrm{~m}^{-2}\right)$ of net CRF during MAM. In addition, the highest values of CRF signify maximum AOD in the lower atmosphere [21], [29] - [32].

Saud et al. [21] found that, in the presence of high AOD, the SWCRF (cooling) may dominate over LWCRF (warming), results in negative CRF. However, other factors may also influence this aspect e.g., clouds types and most of the meteorological parameters (wind, temperature and humidity). Almost, the eastern part of the study domain found medium to low values of net CRF in the rest of the seasons. In addition, the LWCRF is seen prominent over the entire study area with the highest values of $\sim 60 \mathrm{~W} \mathrm{m-}{ }^{2}$ in JJA and average to low in some parts of the southeastern sites during MAM (figure not shown). Seasonally, the eastern parts of the study region showed the lowest contribution of all types of CRFs. Recently, Saud et al. [21] and Bao et al. [22] have analyzed the spatial and seasonal heterogeneity in SWCRF and LWCRF for the CERES data set and found almost similar results as ours with certain noticeable seasonal differences. Moreover, they have noticed an overall net cooling effect at the TOA for the study period.

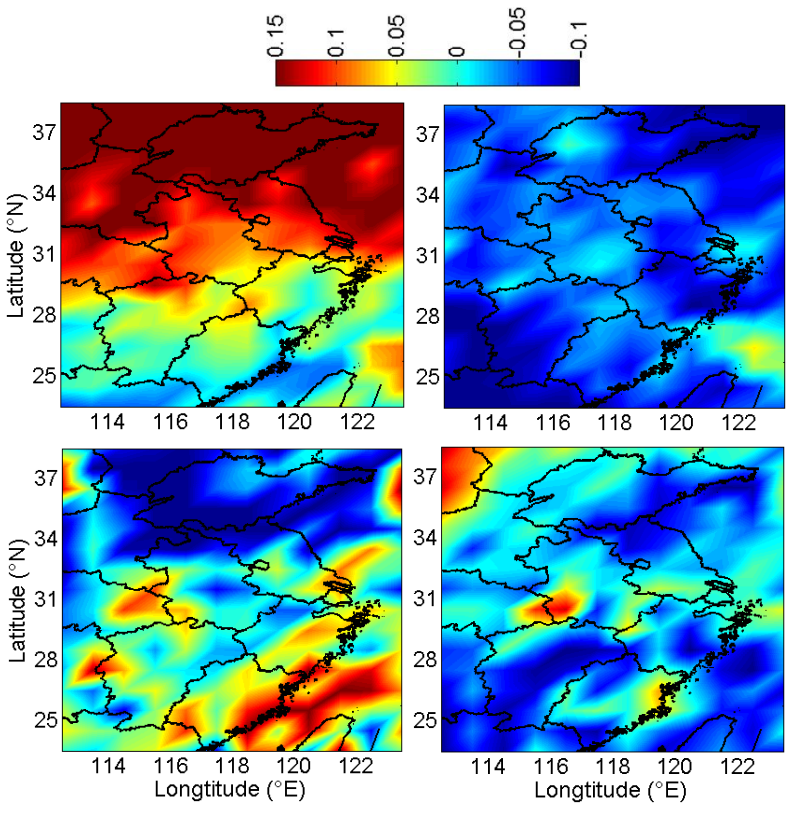

Figure. 3. Same as in Fig. 2, but for the seasonal mean relative tendencies in AI. The representation of seasons is same as given in Fig. 2.

In a long term analysis conducted by Saud et al. [21] over the Indian monsoon region, the distribution was observed to be similar to our study region. The recent decadal studies conducted in the world revealed that the SWCRF found decreased over the ocean but increased over land. The reason is due to an increase in aerosol over land, and increase in cloud albedo. Meanwhile, the LWCRF also demonstrated a large frequency mode for the two seasons DJF and SON, in the bin interval ranging from 20 to $30 \mathrm{Wm}^{-2}$ accounting $33.3 \%$ and $27.2 \%$ of their respective distribution. The positive long tail in the mean LWCRF is prominent for JJA only. Our seasonal pattern for JJA is in line with the findings of Bao et al. [22], and Saud et al. [21] reported during a different time period and for the distinct environment. However, the highest negative net CRF $\left(-120 \mathrm{~W} \mathrm{~m}^{-2}\right)$ was observed during the MAM season (Figure 4).

The frequency distributions of CRFs during the four seasons are shown in Figure 5. The bin intervals in the present study for all the CRFs were set with an increment of $10 \mathrm{Wm}^{-2}$. The largest negative frequency for SWCRF was found in the bin size of -80 to $-60 \mathrm{Wm}^{-2}$, accounting $26.5 \%, 25 \%$ and $19 \%$ during DJF, SON and MAM, respectively, followed by the bin intervals from -20 to $-40 \mathrm{~W} \mathrm{~m}^{-2}$. However, the bin intervals between -100 and $-80 \mathrm{Wm}^{-2}$ had the highest frequency during JJA, accounting for $29.4 \%$ out of the total distribution. Overall, the SWCRF distribution revealed that the highest $\left(-180 \mathrm{Wm}^{-2}\right)$ and lowest $\left(-110 \mathrm{Wm}^{-2}\right)$ values were noticed during JJA and DJF, respectively.

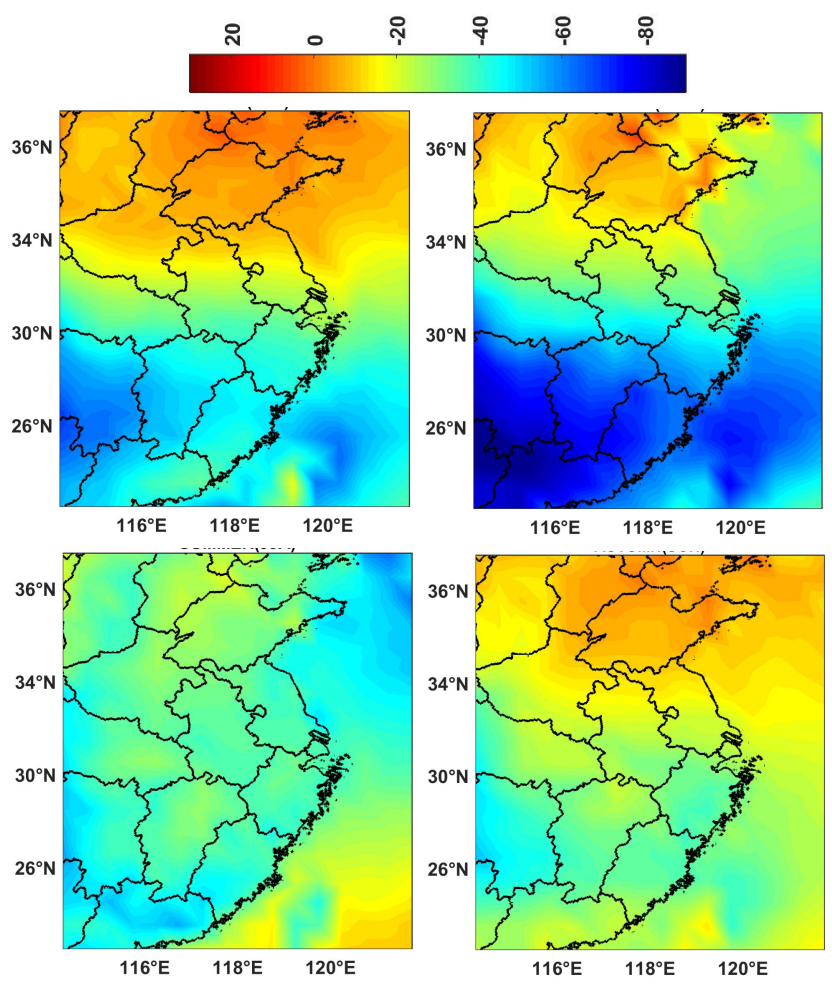

Figure. 4. Spatial distributions of cloud radiative forcing $\left(\mathrm{CRF}\right.$, in $\left.\mathrm{Wm}^{-2}\right)$ in different seasons over the study domain during 2004-2016. The different panels represent CRF for the net radiations observed from the CERES sensor. 


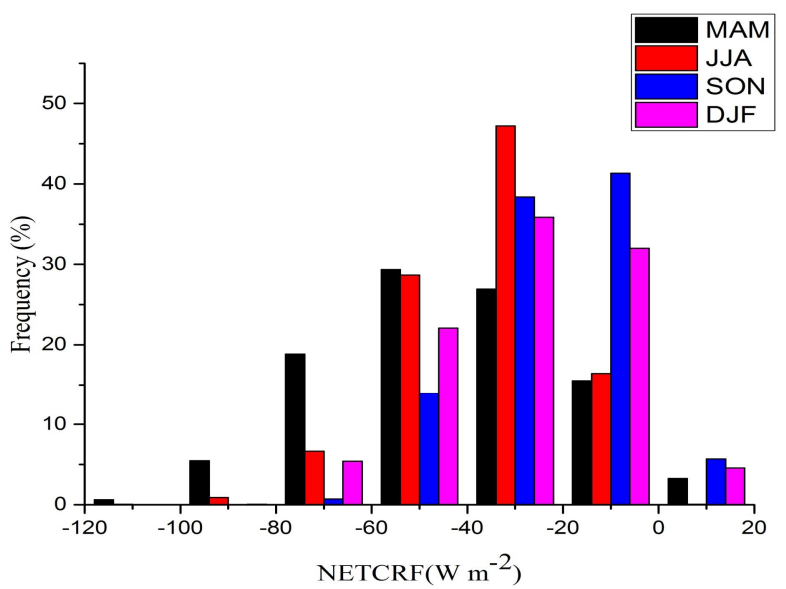

Figure. 5. Seasonal frequency distributions of net CRF observed from CERES over East China.

\section{CONCLUSION}

The key conclusions obtained from the results of this study are listed below:

1. High AI $(>1.1)$ and low AI $(<0.8)$ with moderate values of 0.8-1.1 were noticed in the south, north and central portions of East China. The large values of $\mathrm{AI}$ in spring over the North part of East China is attributed to dominance of aerosol sources, besides the strong association and mix up of shallow boundary layer with the dust particles originated from the desert regions located in Northwest of China.

2. On seasonal basis, the relative tendencies of AI showed highest values in the winter and lowest in the spring which is quite similar to that found in the seasonal means of AI over the study domain.

3. The spatial variations in SWCRF and LWCRF is closely related to variability in CTP, COD and CF. Also, the results in the present study highlighted a strong negative SWCRF $\left(-120 \mathrm{~W} \mathrm{~m}^{-2}\right)$ and positive LWCRF $\left(60 \mathrm{~W} \mathrm{~m}^{-2}\right)$ during MAM and JJA, respectively over southern regions of the study domain.

4. The SWCRF frequency distribution revealed that the highest $\left(-180 \mathrm{Wm}^{-2}\right)$ and lowest $\left(-110 \mathrm{Wm}^{-2}\right)$ values were noticed during JJA and DJF, respectively.

\section{ACKNOWLEDGEMENT}

The authors acknowledge the CERES and OMI scientific data teams for providing and processing various datasets used in this study and to NCEP/NCAR for providing reanalysis meteorological datasets. We thank and are grateful to the Department of Science and Technology (DST), Government of India for the award of DST-FIST Level-1 (SR/FST/PS-1/2018/35) scheme to Department of Physics, KLEF. One of the authors KRK indebted the DST-SERB for granting fund through Start-up Research Grant (SRG) Scheme (Grant No. SRG/2020/001445).

\section{CONFLICT OF INTEREST}

The authors declare no conflict of interest.

\section{REFERENCES}

1. Y. J. Kaufman, I. Koren, L. and A. Remer. The effect of smoke, dust, and pollution aerosol on shallow cloud development over the Atlantic Ocean. Proc. Natl. Acad. Sci., Vol. 102, pp. 11207-11212, Jun 2005.

2. IPCC. Climate Change 2013: The Physical Science Basis. Contribution of Working Group I to the Fifth 4 Assessment Report of the Intergovernmental Panel on Climate Change. 6 Cambridge University Press, Cambridge, United Kingdom And New York, NY, USA, 2013, 1535.

3. V. Ramanathan, P. J. Crutzen, J. T. Kiehl, and D. Rosenfeld. Aerosols, climate, and the hydrological cycle. Science, Vol. 294(5549), pp. 2119-2124, Apr 2001.

4.C.O. Ansari, and S.K.Panda. Analysis of ionospheric TEC from GNSS observables over the Turkish region and predictability of IRI and SPIM models. Astrophysics and Space Science, Vol. 362, Sep 2017.

5. K. R. Kumar, and N.S.M.P. Latha Devi. Column and surface aerosol optical properties and their association with meteorology in the Yangtze River Delta. International Journal of Recent Technology and Engineering (SCOPUS), Vol. 8(4), pp. 1-5, DOI:10.35940/ijrte.DS936.118419, Oct 2019.

6. R. Khan, K.R.Kumar, and T. Zhao. The climatology of aerosol optical thickness and radiative effects in Southeast Asia from 18-years of ground-based observations. Environmental Pollution Vol. 254, pp. 113025, Jun 2019.

7.R. Khan, K.R.Kumar, T. Zhao, and G. Ali. The contribution of different aerosol types to direct radiative forcing over distinct environments of Pakistan inferred from the AERONET data. Environmental Research Letters, doi:10.1088/1748-9326/aba2a6, May 2020.

8. K.R. Kumar, R. Boiyo, R. Khan, N. Kang, and et al. Multi-year analysis of aerosol optical properties and implications to radiative forcing over urban Pretoria, South Africa. Theoretical and Applied Climatology Vol. 141, pp. 343-357, Jan 2020.

9. H. Ding, K. R. Kumar, R. Boiyo, and T. Zhao. The relationships between surface-column aerosol concentrations and meteorological factors observed at major cities in the Yangtze River Delta, China. Environmental Science and Pollution Research Vol. 26, pp. 36568-36588, Sep 2019. 
10. N. Kang, F. Deng, R. Khan, K.R. Kumar, K. Hu, et al. Temporal variations of $P M$ concentration and its association with AOD and meteorology observed in Nanjing during the autumn and winter seasons of 2014-2017. Journal of Atmospheric and Solar Terrestrial Physics Vol. 203, pp.105273, May 2020.

11. D.V. Ratnam, G. Sivavaraprasad, and N.S.M.P. Latha Devi. Analysis of ionosphere variability over low-latitude GNSS stations during 24th solar maximum period. Advances in Space Research, Vol. 60 pp. 419-434, May 2017.

12. H. Pan, W. Huo, M. Wang, J. Zhang, L. Meng, K.R. Kumar, and NSMP. Latha Devi. Insight into the climatology of different sand-dust aerosol types over the Taklimakan Desert based on the observations from radiosonde and $\mathrm{A}$-train satellites. Atmospheric Environment Vol. 238, pp. 117705, Jun 2020.

13. N.S.M.P. Latha Devi, and K.R. Kumar. Inter-comparison of multisensory AOD products observed over East China during 2005-2018. Solid State Technology Vol. 63(5), pp. 1-5, Oct 2020.

14. G. Sivavaraprasad, and D.V. Ratnam. Short-term forecasting of ionospheric total electron content over a low-latitude global navigation satellite system station. IET Radar, Sonar \& Navigation Vol. 11 (8), pp. 1309-1312, Sep 2017.

15. J. Huang, L. Bu, K.R. Kumar, R. Khan, and N.S.M.P. Latha Devi. Investigating the relationship between aerosol and cloud optical properties inferred from the MODIS sensor in recent decades over East China. Atmospheric Environment Vol. 239, pp. 117812, Aug 2020 .

16. D.V. Ratnam, J. R. K. K. Dabbakuti and S. Sunda, Modeling of Ionospheric Time Delays Based on a Multishell Spherical Harmonics Function Approach. IEEE Journal of Selected Topics in Applied Earth Observations and Remote Sensing, Vol. 10, pp. 5784-5790, Dec. 2017.

17. G. Sivavaraprasad, D.V. Ratnam, and Y. Otsuka. Multi-component Analysis of Ionospheric Scintillation Effects Using the Synchrosqueezing Technique for Monitoring and Mitigating their Impact on GNSS Signals. Journal of Navigation, Vol. 72, pp. 669-684, May 2019.

18. O. Torres, P.K. Bhartia, J.R. Herman, Z. Ahmad, and J. Gleason. Derivation of aerosol properties from satellite measurements of backscattered ultraviolet radiation: Theoretical basis. J.Geophys.Res. Vol. 103, pp. 17099-17110, Mar 1998.

19. G. Sivavaraprasad, and D.V. Ratnam. Application of SST to forecast ionospheric delays using GPS observations. IET Radar sonar and navigation, Vol. 11, pp. 1070-1080, Jul 2017.

20. S. Bao, H. Letu, J. Zhao, H. Shang, Y. Lei, et al. Spatiotemporal distributions of cloud parameters and their response to meteorological factors over the Tibetan Plateau during 2003-2015 based on MODIS data. Int. J. Climat. Vol. 39, pp. 532-543, May 2019.

21. T. Saud, S. Dey, S. Das, and S. Dutta. A satellite-based 13-year climatology of net cloud radiative forcing over the Indian monsoon region. Atmos. Res. Vol. 182, pp. 76-86, May 2016.

22. J.R.K.K. Dabbakuti, and D.V. Ratnam. Modeling and analysis of GPS-TEC low latitude climatology during the 24th solar cycle using empirical orthogonal functions. Advances in space research, pp. 1751-1764, Oct 2017.

23. E.C. Weatherhead, C. Gregory, G.C. Reinsel, X.L.M. Tiao, C. Dongseok, K.C. Wai, and K. Teddie, K. Factors Affecting the Detection of Trends: Statistical Considerations and Applications to Environmental Data. J.Geophys.Res. Vol. 103 (D14), pp. 17149. Jun 1998.

24. R. Boiyo, K.R. Kumar, and T. Zhao. Spatial variations and trends in AOD climatology over East Africa during 2001-2015: A comparative study using three satellite datasets. Int. J. Climatology. Vol. 38 (S1), pp. 1221-1240, Aug 2018.

25. B.S. Potula, Y.H. Chu, G. Uma, H.P. Hsia, and K. H. Wu. A global comparative study on the ionospheric measurements between COSMIC radio occultation technique and IRI model. Journal of geophysical research, Vol. 116, pp. A02310, doi:10.1029/2010JA015814, Nov 2017.

26. D.V. Ratnam, Y. Otsuka, G. Siva varaprasad, and J.R.K.K. Dabbakuti. Development of multivariate ionospheric TEC forecasting algorithm using linear time series model and ARMA over low-latitude GNSS station. Advances in Space Research, Vol. 63, pp. 2848-2856, May 2019.

27. G. Uma, Y. Liu, S.P. Chen, SP; Y.Y. Sun, P.S. Brahmanandam, and C.H. Lin. Earth planets and space, 2012, A comparison of the equatorial spread $F$ derived by the International Reference Ionosphere and the $\mathrm{S}-4$ index observed by FORMOSAT-3/COSMIC during the solar minimum period of 2007-2009.

28. D.V. Ratnam, J.R.K.K. Dabbakuti, and N.V.V. N. J. Lakshmi. Improvement of Indian-Regional Klobuchar Ionospheric Model Parameters for Single-Frequency 
GNSS Users. IEEE Geoscience and remote sensing letters, July 2018.

29. N. UmaKanth, G. Ch. Satyanarayana, Simon, Baby and Rao. Some climatological aspects of convective systems at five major cities of West Bengal, India. e-Journal Earth Science India, Vol. 12, pp. 105-116, Aug 2019.

30. V. B. Dodla, G. Ch. Satyanarayana, and Srinivas Desamsetti. Analysis and prediction of a catastrophic Indian coastal heat wave of 2015. Natural Hazards, Vol. 87(1), pp. 395-414, Apr 2017.

31. C. V. Naidu, A. Dharma Raju, P. Vinay Kumar and G. Ch. Satyanarayana. Perceptible changes in Indian summer monsoon rainfall in relation to Indian Monsoon Index. Global and Planetary Change, Vol. 157, Pages 83-92, Oct 2017.

32. V. B. Dodla, G. Ch. Satyanarayana and D. Srinivas. Atmospheric dispersion of $\mathbf{P M}_{2.5}$ precursor gases from two major thermal plants in Andhra Pradesh, India. Aerosol and Air Quality Research, Vol. 17, pp. 381-393, Nov 2017. 